\title{
Metaphase Process
}

National Cancer Institute

\section{Source}

National Cancer Institute. Metaphase Process. NCI Thesaurus. Code C16846.

The second phase of mitosis, in which the chromosomes line up across the equatorial plane of the spindle prior to separation. 